\title{
"Be Careful What You Wish For" Revisited: A Response to Jeff Orleans
}

\author{
Andrew Zimbalist \\ Smith College
}

I appreciate the comity and care with which Jeff Orleans has responded to my paper. He brings years of experience, intelligence and insight to this colloquy. I concur with much of his analysis on the value of college athletics, the appropriateness of a measure of institutional financial support to athletics departments, and the impact of the FBS programs on the rest of Division I and Divisions II and III. I also agree that it makes good sense to attempt to standardize the accounting of college athletics and to make transparent its results. ${ }^{1}$ Similarly, I have no problem with a renewed effort to change the financial culture of college athletics and to support an end to "emergency" funding of athletic department deficits.

My primary disagreement with Jeff Orleans is that I believe it makes no sense to hold potentially significant reforms hostage to the success of an effort (a) to standardize college athletics accounting, (b) to open the accounting books, (c) to change a financial culture that has evolved over the course of the past century and (d) to develop a coherent long-term plan for reform.

The financial problems confronting college athletics are pressing. Deficits are growing and inequalities are sharpening. The rates of increase in athletic spending cannot be sustained in an environment where the underlying financial model of higher education is so fragile. With the cost of college education soaring to over $\$ 50,000$ annually at our nation's top schools, with university endowments suffering from the collapse in the stock market, with projected weakness in our national economy and with the new educational models opened up by the internet, U.S. universities can no longer be indifferent to the profligate spending patterns in intercollegiate athletics.

As I wrote in my initial paper, Jim Isch, Dan Fulks and NACUBO have been involved in a salutary effort to standardize, clarify and make more inclusive accounting practices in college athletics departments. They have made some progress, but there is a long road still to travel. The variations among schools and the accounting conundrums are simply too complex for easy answers. Assuming that a reasonable standardized system is developed some time in the future, there is then the question of getting schools to open their full books to build transparency, and, last but not least, there is the issue of monitoring the system. The latter entails not only preparing a legion of auditors, but also the NCAA filling the type of role that the IRS now does with our tax system. The NCAA will have to be an enforcer, issuing sanctions to schools who file incomplete or inaccurate reports. 
I agree with Jeff Orleans that, if we ever reached a place of open, comprehensive and accurate information about each school, it would help to apply greater pressure on ADs to be fiscally responsible. It would still not be reasonable, however, to expect athletic departments to all of a sudden adhere to a balanced budget philosophy. Why not? First, there would be a host of accounting gimmicks that could be employed: off-budget expenditures; using the basketball arena for a few rock concerts during the year and pushing half of the arena's operating costs and debt service onto the music department or another budget; inadequate accounting for indirect capital and personnel costs; shifting concessions, catering or parking revenue from another department to athletics; identifying a lower charge than the face value of room and board for scholarship athletes; and so on.

Second, there is a basic structural problem that lies at the root of the common deficit experience in athletic departments. Namely, there are no stockholders demanding quarterly profits to boost the value of the company's stock. Instead, there are stakeholders (boosters, students, alums, trustees) who demand victory of a not-for-profit entity. That is, the underlying organizational logic veers resources toward finding victories, not profits. When an additional revenue stream is projected for athletics, ADs easily find a way to spend it in the pursuit of victory. It is this structural circumstance and organizational logic that engenders the lax financial culture that leads to the deficits. This culture has been impervious to previous attempts at budgetary discipline, as it will be to any new attempt that does not attack the underlying structure and logic of intercollegiate athletics.

Jeff Orleans talks about the imposition of "consequences if there are consistent deficits." This gets to the essence of the issue. In a free market environment, the consequence of consistent deficits is bankruptcy. What is the consequence in a nonprofit, stilted market environment? Will the program be closed? Will the AD on a long-term contract be fired, even if he or she has a winning record? The consequences of budgetary indiscipline in a market environment are clear and harsh; not so with intercollegiate athletics.

We all recognize that intercollegiate athletics is a hybrid of professional and amateur elements. Few of us advocate that the amateur element be jettisoned. The conjoining of the two opposite elements, however, implies that the system will always have contradictions and tensions. In my view, the solution to the structural problem is not to completely commercialize the system, subjecting all its parts to the full force of market discipline. Yet, absent market discipline, there must be strong measures, not mere exhortation.

Jeff Orleans appears more sanguine about change from within the NCAA, in part, because of the 1996 restructuring reform. With it, he and others believe that college presidents today have voting control over the NCAA and, therefore, are now in a position to assert budgetary discipline. Perhaps, but the fact of the matter is that presidents have always had the statutory ability to control the NCAA if they wanted to do so. For reasons I outlined in my keynote paper, they have not wanted to do so.

But suppose, against all odds, the hortatory approach works and intercollegiate athletics finds financial discipline. What kind of changes should we expect? There is no basis in Jeff Orleans' package to lead one to anticipate that astronomical coaches' salaries or other areas of excess will be addressed; in the current skewed market of college sports, the prevailing view is that all of these excesses help teams to win. Rather, we are likely to witness a reduction in the sponsorship of sports programs, and, hence, lower student-athlete participation numbers; thereby sub- 
verting the underlying true purpose of college sports. Such has been the strategy of the University of Texas in reducing its intercollegiate competition to an FBS minimum of 16 sports and, then, concentrating the saved resources on football and basketball.

Jeff Orleans closes with a number of observations about being cautious before getting the government involved. His first observation is that: "The athletic community will have more control over the changes that it initiates than over 'reform' that originates in Congress or otherwise is imposed externally." This is probably true, but isn't it also an argument for the NCAA to be proactive around the structuring of legislation that would underwrite an antitrust exemption, rather than waiting for Congress to take action?

There is a related question about whether we can ever expect true reform from an association that has been and continues to be managed by athletics directors, conference commissioners and coaches. And if we can't, then it is a nonstarter to call for effective reform to be initiated by the NCAA. (This should not be read as a criticism of the men and women who run the NCAA. I have the utmost respect for them. It is rather a comment about the structural realities that constrain them.)

Next, Jeff Orleans invokes a series of probability statements about "going to Washington" that seem to come out of thin air. The first is: "It's likely that there will be only one chance to get Congressional action." The history of legislative action provides no support whatsoever for this assertion.

He continues: "some observers might consider the most direct precedents for an antitrust exemption — in the major professional leagues - include overall salary caps and revenue sharing, both of which will be problematic in Division I." This is inaccurate. Baseball obtained its presumed blanket antitrust exemption in 1922, well before there was any talk of salary caps and revenue sharing. Similarly, the NFL, NBA and NHL got their partial exemption for the purpose of cartelizing national sponsored television rights in 1961, well before any of those leagues had a salary cap. The NFL's Congressional permission to merge with the AFL, and the NBA's to join with the ABA, each came well before either league introduced a salary cap or their modern systems of revenue sharing.

Jeff Orleans then asserts: "It seems certain that Congress will expect not simply periodic review of the effects of any exemption, but some means to assure those effects actually will be positive." He attempts to demonstrate this "certainty" by reference to Congressman Tom McMillen's antitrust exemption bill in the 1990s directed at college television. The bill provided an option for Congress to consider direct regulation if the NCAA did not take advantage of its exemption. Thus, Orleans' claim to certainty appears to be based on a sample of one. The fact of the matter is that Congress often passes bills without such provisions. For instance, in 1998 it passed the Curt Flood Act in baseball which lifted baseball's exemption in the realm of labor relations. There was no provision for oversight and intervention. Nonetheless, if the Congress were to grant the NCAA an antitrust exemption for the purpose of controlling coaches' salaries and the NCAA did nothing, then why shouldn't Congress take matters into its own hands and impose some controls?

Let us remember that government is already very involved in college sports through Title IX, Pell Grants, tax exemptions and privileges, periodic hearings, investigations and reports, facility and infrastructure investment (state government), inter alia. Congress certainly doesn't need the pretext of an antitrust exemption to notice the existence of or seek to influence college sports. 
Orleans writes that an exemption might create "the expectation that the IRS would have the right to determine if the resulting framework would be consistent with its 'excess compensation' standards for highly-paid employees in tax-exempt entities." But through the private inurement or private benefit doctrines, the IRS already has the right to do this, if they so choose. ${ }^{2}$

What is true, as Jeff Orleans suggests, is that if the NCAA goes to Congress for an antitrust exemption, it would make perfect sense for the NCAA to clearly define what the scope of the exemption should be. That is, should the NCAA be able to impose cost controls, not only on coaches' salaries, but also on recruitment expenditures, stadium spending, AD compensation, tutoring centers for athletes, travel policies - all areas that are intended to attract the best athletes to their school which they cannot do through the normal market mechanism of offering higher salaries to prospective student-athletes? Or should the exemption be limited to a subset of these items? An argument for restricting the exemption to the compensation of coaches and ADs is that such a limitation would have no impact on the quality of the football and basketball being played (because the excess payment is all economic rent) and because it would begin to preserve some ethical consistency if coaches and ADs were not paid more than the highest paid professors or than the university president at an institution whose priority is supposed to be education, not sports. There are many complicated issues involved in delineating the scope of any exemption, and it is a subject that would need to be discussed at some length by NCAA committees, lawyers and politicians in Washington.

As I stated in my original paper, I have no illusions that any of my proposed reforms will come to pass in the near future. The restriction of football scholarships is the reform in nearest grasp. A football playoff and an antitrust exemption require much more work. True reform is never easy. Interim NCAA President Jim Isch commented to USA Today that my talk at the colloquium was "a stretch." (Wieberg, 2010) I think Jim was right. It was intended to be a stretch. Any reform worth having is a reform worth fighting for. If there's no stretch, there's no real reform.

\section{Notes}

1. Although I note that Mr. Orleans appears to conflate a balance sheet with an income statement.

2. Colombo confuses the matter when he asserts that if a college coach is paid as much as a professional coach, then he must be receiving compensation of fair market value. As I argued in my keynote paper, if the college team has a revenue one-fifth that of the pro team and the coaches of the two teams receive near equal salaries, this outcome is not consistent with a finding of fair market value. In any event, under the private benefit doctrine, compensation can be deemed excessive even if it is at fair market value.

\section{References}

Colombo, J. (forthcoming).The NCAA, Tax Exemption and College Athletics. Illinois Law Journal.

Wieberg, S. (2010). Economist Adds to College Football Playoff Calls. USA Today, January, 13. 